\title{
Preparation and Ethanol Sensing Properties of ZnO Nanoparticles via a Novel Sol-Gel Method
}

\author{
A. Ahmadi Daryakenari, ${ }^{1}$ M. Ahmadi Daryakenari, ${ }^{2}$ Y. Bahari, ${ }^{1}$ and H. Omivar ${ }^{2}$ \\ ${ }^{1}$ Materials and Energy Research Center, P.O. Box 31787-316, Karaj, Iran \\ ${ }^{2}$ Amirkabir University of Technology, 424 Hafez Ave, P.O. Box 15875-4413, Tehran, Iran
}

Correspondence should be addressed to A. Ahmadi Daryakenari, ahmad.ahmadi1361@yahoo.com

Received 26 October 2011; Accepted 8 December 2011

Academic Editors: R. Alexandrescu and D. Tsoukalas

Copyright (c) 2012 A. Ahmadi Daryakenari et al. This is an open access article distributed under the Creative Commons Attribution License, which permits unrestricted use, distribution, and reproduction in any medium, provided the original work is properly cited.

\begin{abstract}
$\mathrm{ZnO}$ nanoparticles were prepared using a novel sol-gel method. Chemical reactions were carried out between zinc acetate and methanol under ambient conditions using monoethanol amine (MEA) as surfactant and subsequent heating at $200^{\circ} \mathrm{C}$. The powders were calcined, pressed into pellets, and presintered. The properties of the product were characterized by X-ray diffraction (XRD), scanning electron microscopy (SEM), and Fourier transform infrared (FTIR) spectra. For gas sensing experiment, ethanol was used as testing gas. The gas sensing results showed that the maximum value for detecting of 1000 ppm ethanol vapor was 25 at an operating temperature of $370^{\circ} \mathrm{C}$.
\end{abstract}

\section{Introduction}

Oxide semiconductor nanostructures have been widely investigated in recent years because of their excellent properties [1] and application in novel optical, electrical, and mechanical devices such as photovoltaic solar cells, luminescence, biomedicine, photocatalysis, light-emitting diodes (LEDs), varistors, and optoelectronic nanodevices [2-6].

$\mathrm{ZnO}$ is an n-type II-VI semiconductor with wide band gap of $3.37 \mathrm{eV}$, large exciton binding energy $(\sim 60 \mathrm{meV})$, strong emission, large saturation velocity $(\sim 3.2 \times 107 \mathrm{~cm} / \mathrm{s})$, and high breakdown voltage $[7,8]$. These properties make it a promising material for optoelectronic devices in the ultraviolet (UV) and blue region of the electromagnetic spectrum [9], optical or display devices, solar cells $[9,10]$ catalysis [11], cantilevers production, piezoelectric applications [6], superficial acoustic waves (SAW) [12], and humidity [11] and gas sensors [13]. Furthermore, $\mathrm{ZnO}$ has high transparency, chemical and thermal stability, high conductance, and it is nontoxic, inexpensive, and one of the few oxides that exhibit quantum confinement effects in an experimentally accessible size range $[2,3] . \mathrm{ZnO}$ nanostructures which can come in different shapes such as nanowires, nanobelts, nanorods, nanotubes, and nanoparticles can exhibit interesting physical and chemical properties not found in other nanostructures $[14,15] . \mathrm{ZnO}$ in pure and doped form has been intensively studied, and $\mathrm{ZnO}$ gas sensor elements have been prepared and studied in different forms, mostly as thin films, thick films, single crystals, wintered pellets, and hetero junctions while not many have been reported in the bulk form $[16,17]$. Various methods have been used for the production of $\mathrm{ZnO}$ nanostructures, such as vapor-liquid-solid (VLS) method, reaction-vapor deposition, physical vapor deposition, pulsed-laser deposition, thermal evaporation, metal organic chemical vapor deposition (MOCVD), which utilize expensive equipment and are energy consuming (the working temperature is higher than $400^{\circ} \mathrm{C}$ ) and chemical solution routs like sol-gel, coprecipitation, hydrothermal, and template-based methods $[15,18,19]$. In comparison with bulk $\mathrm{ZnO}$, nanocrystalline $\mathrm{ZnO}$ gas sensors have drawn interest due to their application in detecting hydrogen [19], pollutants and toxic gases [13], organic compounds [20,21], alcohols $[19,22,23]$, moisture $[11,24]$, and so forth. The aim of the present work is to synthesize and characterize the novel sol-gel-prepared $\mathrm{ZnO}$ nanoparticles and to investigate the ethanol sensing properties of such nanoparticles. 


\section{Experimental}

All the reagents used in our experiments were prepared from MERC with $99.0 \%$ purification. Zinc acetate dihydrate (Zn $\left.\left(\mathrm{CH}_{3} \mathrm{COO}\right)_{2} \cdot 2 \mathrm{H}_{2} \mathrm{O}\right)$ was used as zinc source. Methanol and MEA were applied as solvent and surfactant, respectively. The molar ratio of MEA to zinc acetate dihydrate was maintained at 1.0, and the concentration of zinc acetate was adjusted at $0.5 \mathrm{~mol} / \mathrm{L}$. First, zinc acetate dihydrate was dissolved in a mixture of methanol and MEA at room temperature. After vigorous stirring using a magnetic bar for $1 \mathrm{~h}$, the solution became homogeneous and clear and allowed to age for $24 \mathrm{~h}$. Then the aged solution was heated at $200^{\circ} \mathrm{C}$ for $3 \mathrm{~h}$. The remaining black sediment at the bottom of the container is our green nanoparticle (GNP). Next, the GNP calcined at $500^{\circ} \mathrm{C}$ (which determined by TG/DTA analysis), and a white powder was obtained (calcined nanoparticle $(\mathrm{CNP})$ ). For evaluating sensor properties, pellets (diameter $13 \mathrm{~mm}$ and thickness $1.5 \mathrm{~mm}$ ) were prepared from the CNP using hydraulic press and applying 2 tones for $2 \mathrm{~min}$ and subsequently presintering at $400^{\circ} \mathrm{C}$ for $1 \mathrm{~h}$. The gas sensing properties were evaluated at various concentrations of ethanol gas and several operating temperatures, from $300^{\circ} \mathrm{C}$ to $400^{\circ} \mathrm{C}$, by measuring the changes of resistance of the sensor in air and in gas.

The crystal structure of GNP was characterized by X-ray diffraction (XRD) (Philips, Model PW3710, $\lambda(\mathrm{Cu} k \alpha)=$ $1.54 \AA$ ). The XRD pattern of GNP is represented in Figure 1 . All the diffraction peaks could be indexed to hexagonal wurtzite $\mathrm{ZnO}$ according to standard JCPDS card no. 36$1451, a=0.3249 \mathrm{~nm}, c=0.5206 \mathrm{~nm}$ with high crystallinity. By applying the Debye-Scherrer formula $D=k \lambda /(\beta \cos \theta)$, where $D$ is the main crystallite size, $\lambda$ is the wavelength of the $\mathrm{X}$-ray radiation $(1.54 \AA), k$ is a constant to be taken as $0.9, \beta$ is the full width at half maximum height of the peak (FWHM), and $\theta$ is the diffraction angle, resulting in the $21 \mathrm{~nm}$ crystallite size for the as-prepared GNP.

Because the XRD pattern could not detect the noncrystalline materials, it should be noted that since in, this study, we used organic solvents and a surfactant, There is some possibility that they still remain in the black sediment and are not completely removed.

The IR spectrum of GNP (Figure 2) exhibits absorption peaks. The broad absorption band centered at $3438 \mathrm{~cm}^{-1}$ is attributed to the band $\mathrm{O}-\mathrm{H}$ stretching vibrations, and the band at $1557 \mathrm{~cm}^{-1}$ is primarily due to the bending vibration of $\mathrm{N}-\mathrm{H}$. The band at $1422 \mathrm{~cm}^{-1}$ is attributed to the bending mode (H-C-H). The bands around 1281, 1021, and $546 \mathrm{~cm}^{-1}$ are related to the vibration of $\mathrm{C}-\mathrm{N}, \mathrm{C}-\mathrm{O}$, and $\mathrm{Zn}-$ $\mathrm{O}$, respectively. Hence, the FTIR data confirms the presence of organic compounds. The suggestion for such reactions could be as Scheme 1 [25].

Figure 3 shows the TG/DTA curve of GNP. There is no significant weight loss before $200^{\circ} \mathrm{C}$ since our working temperature was at $200^{\circ} \mathrm{C}$. At this temperature, thermal decomposition begins gradually, and the sharp peak in DTA graph is attributed to the elimination and decomposition of zinc alkoxide by organic compounds.

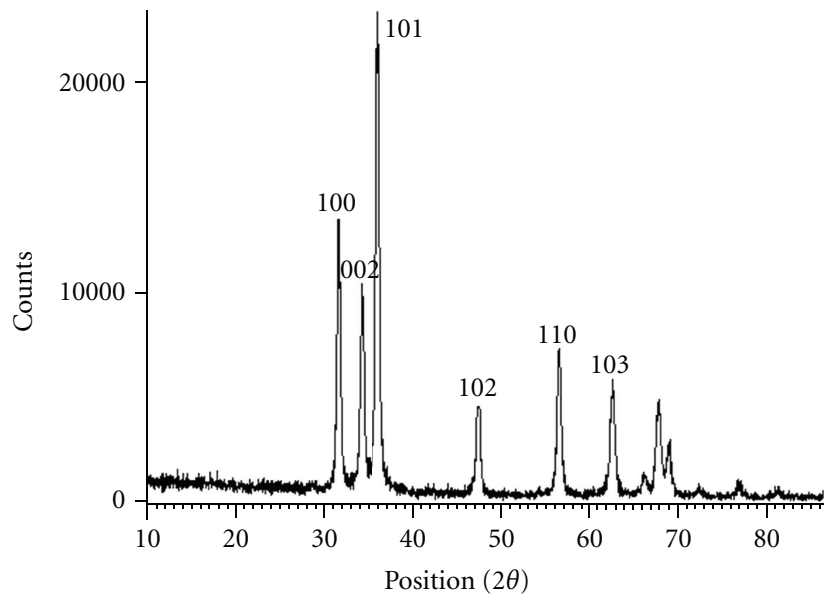

FIGURE 1: XRD pattern of GNP. All the peaks can be assigned to $\mathrm{ZnO}$.

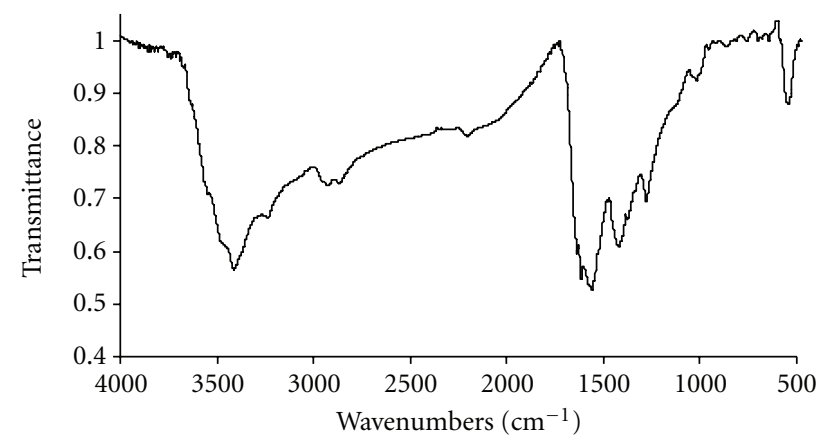

FIgURE 2: The FT-IR spectra of GNP.

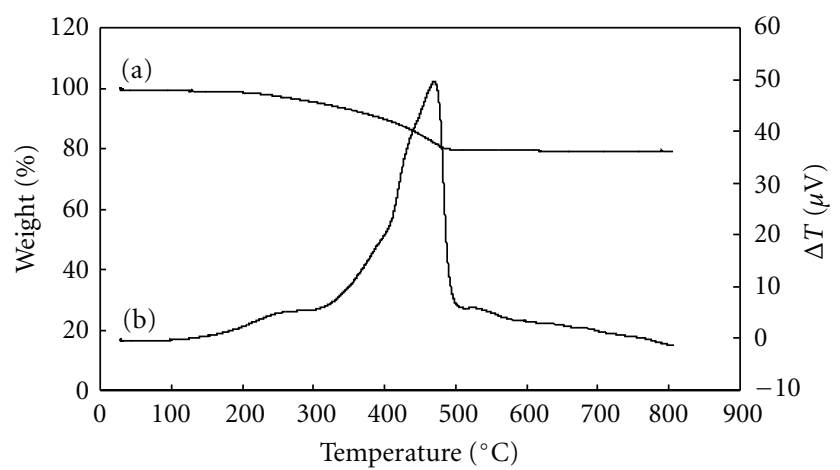

Figure 3: (a) TG, (b) DTA graph of GNP.

A weight loss of about $20 \mathrm{wt} \%$ is observed before $475^{\circ} \mathrm{C}$ is reached. At this point, all organic compounds have volatilized such that the molecule will be stable and its weight nearly constant as illustrated in the DTA graph.

The XRD patterns of the CNP and pellets are represented in Figure 4. In comparison with Figure 2, there is no change in diffraction peaks. Therefore, a zinc oxide (without organic compounds) with the same crystal structure is established. By applying the Debye-Scherrer formula, the main crystallite size would be $39 \mathrm{~nm}$ for CNP and $42 \mathrm{~nm}$ for pellets. 


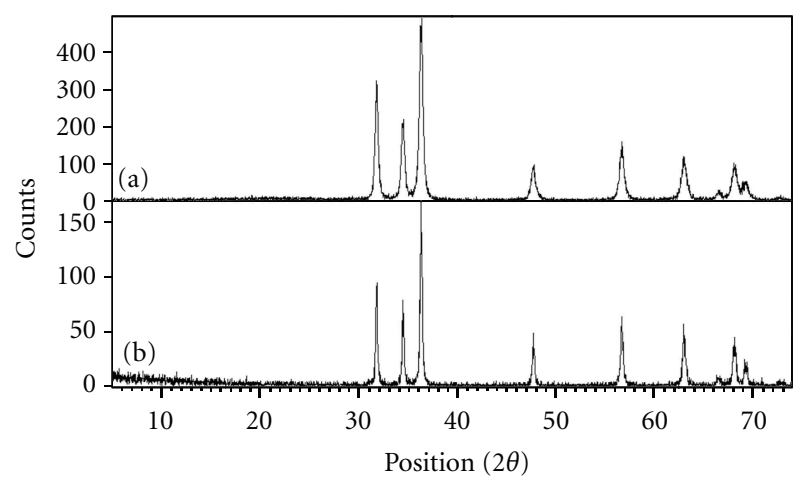

FIgure 4: (a) The XRD patterns of the CNP and (b) pellets.

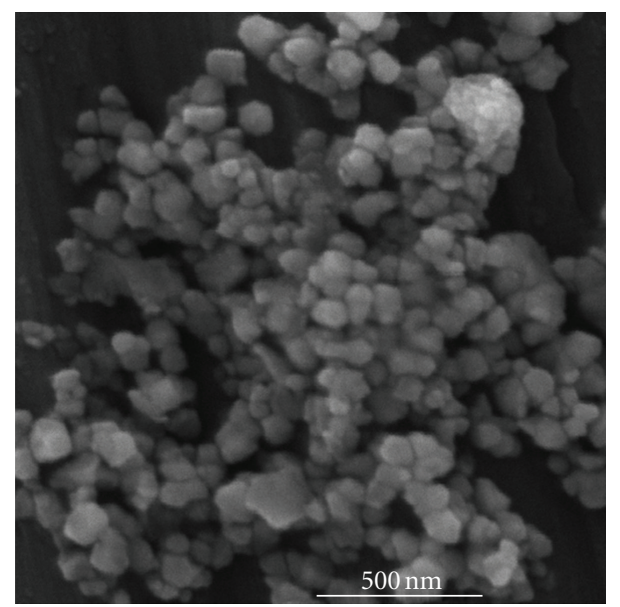

(a)

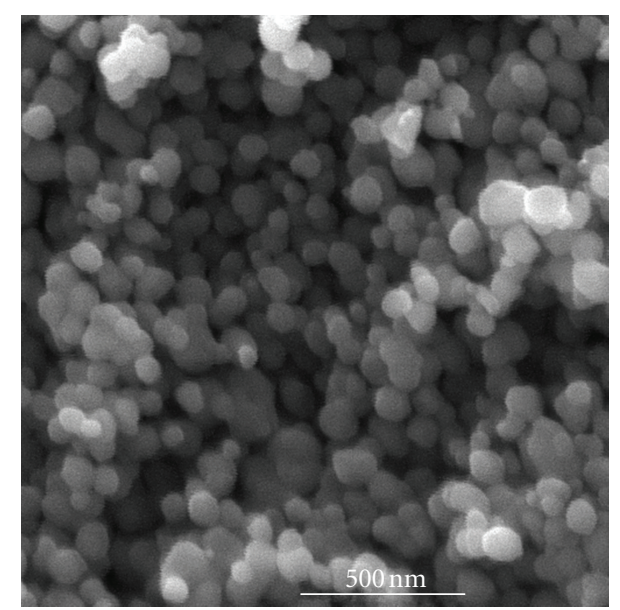

(b)

Figure 5: SEM image of (a) GNP and (b) pellets.

The growth of crystallite size is easily attributed to the relatively high temperature of calcinations and following press.

Figure 5(a) shows the SEM image of GNP. Most of the particles have a size less than $80 \mathrm{~nm}$ with relatively good distribution and near spherical morphology. The SEM image of pellets is shown in Figure 5(b). Pellets have a small growth (less than $10 \mathrm{~nm}$ ) in size, but their morphologies totally transferred to spherical.

The sensitivity of pellets in the experiment to the ethanol gas could be defined as $S=R_{a} / R_{g}$ where $R_{a}$ is the sample resistance measured in the air and $R_{g}$ is sample resistance under ethanol gas.

Figure 6 describes the sensitivity changes of pellets versus operating temperature at the concentration of $1000 \mathrm{ppm}$ of ethanol gas. It could be observed that sensitivity will increase with increasing temperature from $300^{\circ} \mathrm{C}$ to $370^{\circ} \mathrm{C}$ where sensitivity reaches a maximum value of 25 at $370^{\circ} \mathrm{C}$. After that, the sensitivity suddenly decreases to 19 at $390^{\circ} \mathrm{C}$. Since sensitivity is related to both $R_{a}$ and $R_{g}$, the sudden decrease may be attributed to two reasons.

First is the widely accepted phenomenon of chemisorptions when an n-type semiconductor gas sensor presented in air. Chemisorption of oxygen molecules could happen on the surface in the form of $\mathrm{O}^{2-}, \mathrm{O}_{2}{ }^{2-}$, and $\mathrm{O}_{2}{ }^{-}$ions by capturing electrons from the conductance band, since the electronegativity of oxygen molecules is higher than semiconductor. As a result, an electron-depleted space-charge layer in the surface region of the particle will be produced (Figure 7). Takata et al. found that the stable oxygen ions were $\mathrm{O}_{2}{ }^{-}$below $100^{\circ} \mathrm{C}, \mathrm{O}^{-}$between 100 and $300^{\circ} \mathrm{C}$, and $\mathrm{O}^{2-}$ above $300^{\circ} \mathrm{C}$ [26].

Therefore, oxygen adsorption plays an important role in the resistance of pellets, and the amounts of such chemisorbed oxygen species depend strongly on the temperature.

Before $370^{\circ} \mathrm{C}$, air resistance increases with increasing temperature. Since the oxygen species capture conduction electrons from the materials, this leads to a decrease in the electron concentration [22], and the depletion layer becomes larger because of the higher concentration of the adsorbed oxygen. But above $370^{\circ} \mathrm{C}$, the decrease in $R_{a}$ occurs since the adsorption reaction is exothermic and the reaction $\left(\mathrm{O}_{2}+\right.$ $\left.2 \mathrm{e} \rightarrow 2 \mathrm{O}^{-}, \mathrm{O}^{-}+\mathrm{e} \rightarrow \mathrm{O}^{2-}\right)$ will proceed to the left. This causes the reduction of the trapped electrons from the conductance band [27] and the enlargement of the depletion layer.

The next reason could be attributed to $R_{g}$. In the presence of the test gas (R), chemisorption of gas molecules to the surface will result in $\mathrm{RO}$ molecules. As the temperature increases to $370^{\circ} \mathrm{C}$, there is greater adsorption of $\mathrm{RO}$ molecules (since the RO molecules leave the surface and the active sites remain free for the other gas molecules). As a result, charging of electrons in the conduction band occurs, the depletion layer becomes smaller, and the $R_{g}$ drops which is followed by an increase in the sensitivity. The reaction is expressed as follows $[22,28]$ :

$$
\begin{aligned}
& \mathrm{R}_{\text {gas }} \longleftrightarrow \mathrm{R}_{\mathrm{ads}} \\
& \mathrm{O}_{2(\mathrm{gas})}+2 \mathrm{e}^{-} \longleftrightarrow 2 \mathrm{O}_{(\mathrm{ads})}^{-} \\
& \mathrm{O}_{2(\mathrm{ads})}^{2-}+2 \mathrm{e}^{-} \longleftrightarrow 2 \mathrm{O}_{(\mathrm{ads})}^{2-} \\
& \mathrm{R}_{(\mathrm{ads})}+\mathrm{O}^{2-}{ }_{(\mathrm{ads})} \longleftrightarrow \mathrm{RO}+2 \mathrm{e}^{-} .
\end{aligned}
$$


<smiles>[Z17]OC(=O)C[Te]CC(=O)O[Ga]OC(C)=O</smiles><smiles>CC(=O)OCCN(CCO)[Al]OC(=O)[18O]CCO</smiles><smiles>O=C([CH2+]O)O[14CH2]O</smiles><smiles>CC(=O)O[14CH2]OC[14CH2]N[14CH2]C[14CH2]O</smiles><smiles>OCCN(CCO)[NH+](CCO)[Ga]O</smiles><smiles>OCCO[Ga]O[Ga]N([Al]CCO)[Te]O</smiles>

Scheme 1

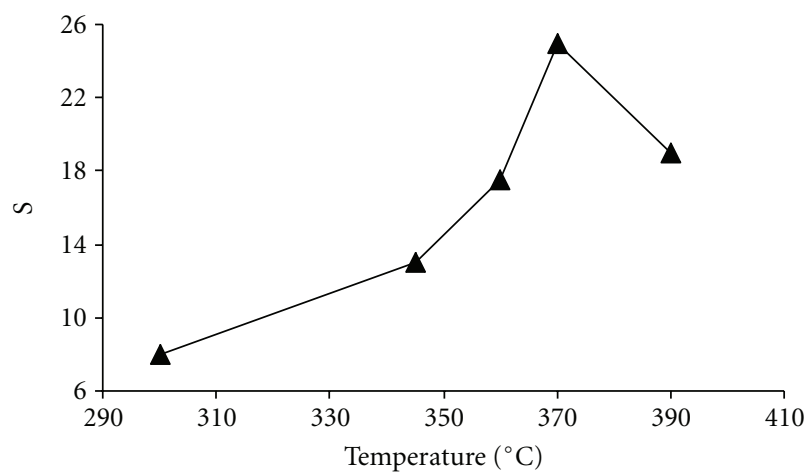

FIgURE 6: Sensitivity of pellets in various temperatures.

Here the testing gas is ethanol, and therefore,

$$
\begin{gathered}
\mathrm{C}_{2} \mathrm{H}_{5} \mathrm{OH}_{(\mathrm{ads})}+6 \mathrm{O}^{2-}{ }_{(\text {ads })} \longrightarrow 2 \mathrm{CO}_{2(\text { gas })} \\
+3 \mathrm{H}_{2} \mathrm{O}_{(\text {gas })}+12 \mathrm{e}^{-}
\end{gathered}
$$

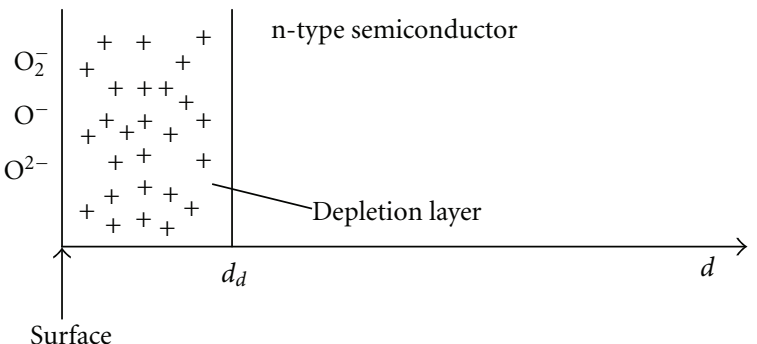

FIGURE 7: Electron-depleted layer model ( $d$ is distance from surface and $d_{d}$ is depth of depletion layer).

where the subscripts gas and ads, mean gas and adsorbed respectively.

After that, the physisorption rate of $\mathrm{R}$ molecules will decrease. Therefore, fewer electrons will be charged in the conduction band and the larger depletion layer causes an increase in $R_{g}$. 


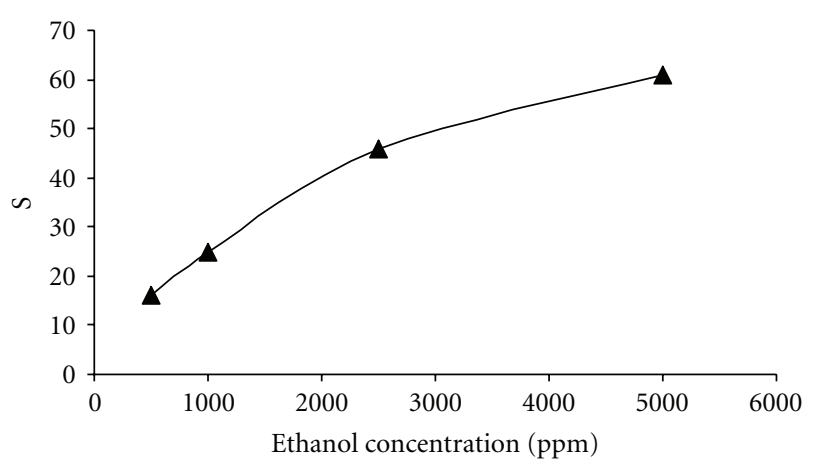

Figure 8: Relationship between the ethanol concentration and sensitivity.

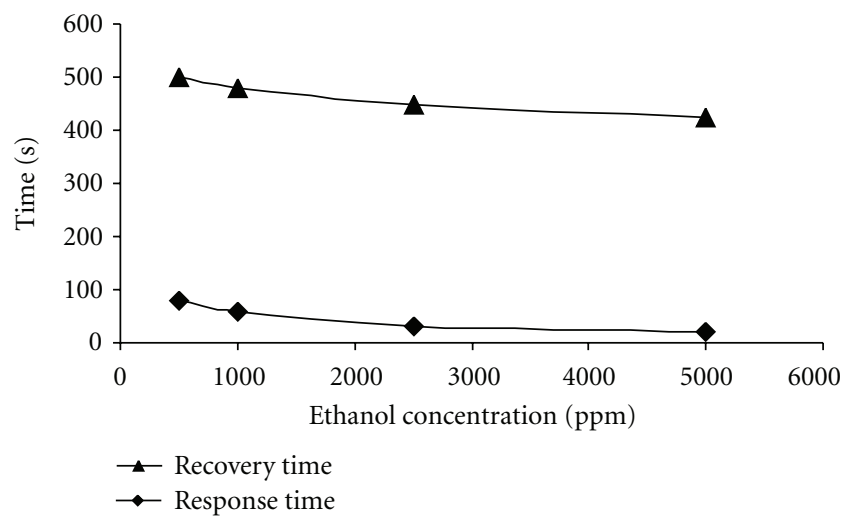

FIGURE 9: Relationship between ethanol concentration and both response and recovery time.

The effect of ethanol concentration on sensitivity at $370^{\circ} \mathrm{C}$ is described in Figure 8. As would be expected, the sensitivity will be enhanced by presenting further ethanol concentration. The slope of the curve drops and the sensitivity will reach a saturation value in the large ethanol concentration due to the fact that the active sites of surface will be occupied by more ethanol molecules until the surface is completely covered by gas molecules.

Figure 9 shows the effect of ethanol concentration on both response time (the time in which the gas resistance reaches $90 \%$ of its maximum value) and recovery time (the time in which the air resistance reaches $90 \%$ of its maximum value after removing the gas). By providing more ethanol gas, it can be expected that the depletion layer would be tightened since more electrons will charge in the conductance band according to (5). As a result, response time will be reduced. Similar description is applicable for recovery time.

\section{Conclusion}

In summary, $\mathrm{ZnO}$ nanoparticles were synthesized using the sol-gel technique. The minimum temperature for calcination of GNP was determined at $475^{\circ} \mathrm{C}$ by TG-DTA curve. The $\mathrm{CNP}$ was pressed to pellets and presintered at $400^{\circ} \mathrm{C}$. Crystallite size for pellets was determined to be $42 \mathrm{~nm}$ from XRD. SEM image showed that the majority of particles have a size less than $90 \mathrm{~nm}$ with relatively good distribution and nearspherical morphology. In the ethanol sensing experiment, sensitivity reached a maximum value of 25 at $370^{\circ} \mathrm{C}$ and then decreased to 19 at $390^{\circ} \mathrm{C}$ for $1000 \mathrm{ppm}$ of ethanol concentration. By increasing the concentration of ethanol, the sensitivity was enhanced and both response and recovery time dropped. Therefore, sol-gel-prepared $\mathrm{ZnO}$ pellets have been shown to demonstrate excellent sensing properties.

\section{Acknowledgment}

The authors would like to thank the Electrochemistry Laboratory of the Materials and Energy Research Center for its support.

\section{References}

[1] Y. Bahari Molla Mahaleh, S. K. Sadrnezhaad, and D. Hosseini, "NiO nanoparticles synthesis by chemical precipitation and effect of applied surfactant on distribution of particle size," Journal of Nanomaterials, vol. 2008, no. 1, Article ID 470595, 4 pages, 2008.

[2] J. Xu, J. Han, Y. Zhang, Y. Sun, and B. Xie, "Studies on alcohol sensing mechanism of $\mathrm{ZnO}$ based gas sensors," Journal of Sensors and Actuators, B, vol. 132, no. 1, pp. 334-339, 2008.

[3] G. Xing, G. Chen, X. Song, X. Yuan, W. Yao, and H. Yan, " $\mathrm{ZnO}$ and $\mathrm{TiO}_{2}$ nanoparticles encapsulated in boron nitride nanocages," Journal of Microelectronic Engineering, vol. 66, no. 1-4, pp. 70-76, 2003.

[4] M. H. Liao, C. H. Hsu, and D. H. Chen, "Preparation and properties of amorphous titania-coated zinc oxide nanoparticles," Journal of Solid State Chemistry, vol. 179, no. 7, pp. 20202026, 2006.

[5] N. Boukos, C. Chandrinou, K. Giannakopoulos, G. Pistolis, and A. Travlos, "Growth of $\mathrm{ZnO}$ nanorods by a simple chemical method," Journal of Applied Physics A, vol. 88, no. 1, pp. 35-39, 2007.

[6] M. C. Carotta, A. Cervi, V. di Natale et al., " $\mathrm{ZnO}$ gas sensors: a comparison between nanoparticles and nanotetrapods-based thick films," Journal of Sensors and Actuators, B, vol. 137, no. 1, pp. 164-169, 2009.

[7] X. Zi-qiang, D. Hong, L. Yan, and C. Hang, "Al-doping effects on structure, electrical and optical properties of c-axisorientated ZnO:Al thin films," Materials Science in Semiconductor Processing, vol. 9, no. 1-3, pp. 132-135, 2006.

[8] W. Jun and Y. Yintang, "Deposition of K-doped p type $\mathrm{ZnO}$ thin films on (0001) $\mathrm{Al}_{2} \mathrm{O}_{3}$ substrates," Journal of Materials Letters, vol. 62, no. 12-13, pp. 1899-1901, 2008.

[9] S. A. M. Lima, M. Cremona, M. R. Davolos, C. Legnani, and W. G. Quirino, "Electroluminescence of zinc oxide thin-films prepared via polymeric precursor and via sol-gel methods," Thin Solid Films, vol. 516, no. 2-4, pp. 165-169, 2007.

[10] Y. Caglar, S. Ilican, M. Caglar, and F. Yakuphanoglu, "Effects of In, $\mathrm{Al}$ and $\mathrm{Sn}$ dopants on the structural and optical properties of $\mathrm{ZnO}$ thin films," Journal of Spectrochimica Acta-Part A, vol. 67, no. 3-4, pp. 1113-1119, 2007.

[11] B. C. Yadav, R. Srivastava, C. D. Dwivedi, and P. Pramanik, "Synthesis of nano-sized $\mathrm{ZnO}$ using drop wise method and its performance as moisture sensor," Sensors and Actuators, A, vol. 153, no. 2, pp. 137-141, 2009.

[12] H. Gómez and M. de la L. Olvera, "Ga-doped $\mathrm{ZnO}$ thin films: effect of deposition temperature, dopant concentration, 
and vacuum-thermal treatment on the electrical, optical, structural and morphological properties," Journal of Materials Science and Engineering B, vol. 134, no. 1, pp. 20-26, 2006.

[13] Y. S. Sonawane, K. G. Kanade, B. B. Kale, and R. C. Aiyer, "Electrical and gas sensing properties of self-aligned copperdoped zinc oxide nanoparticles," Journal of Materials Research Bulletin, vol. 43, no. 10, pp. 2719-2726, 2008.

[14] G. Srinivasan, R. T. Rajendra Kumar, and J. Kumar, "Influence of $\mathrm{Al}$ dopant on microstructure and optical properties of $\mathrm{ZnO}$ thin films prepared by sol-gel spin coating method," Optical Materials, vol. 30, no. 2, pp. 314-317, 2007.

[15] X. W. Zhu, Y. Q. Li, Y. Lu, L. C. Liu, and Y. B. Xia, "Effects of $\mathrm{Li}$ or $\mathrm{Li} / \mathrm{Mg}$ dopants on the orientation of $\mathrm{ZnO}$ nanorods prepared by sol-gel method," Journal of Materials Chemistry and Physics, vol. 102, no. 1, pp. 75-79, 2007.

[16] A. B. Bodade, A. M. Bende, and G. N. Chaudhari, "Synthesis and characterization of $\mathrm{CdO}$-doped nanocrystalline $\mathrm{ZnO}$ : $\mathrm{TiO}_{2}$-based $\mathrm{H}_{2} \mathrm{~S}$ gas sensor," Journal of Vacuum, vol. 82, no. 6, pp. 588-593, 2008.

[17] S. H. Jeong, B. N. Park, S. B. Lee, and J. H. Boo, "Metal-doped $\mathrm{ZnO}$ thin films: synthesis and characterizations," Surface and Coatings Technology, vol. 201, no. 9-11, pp. 5318-5322, 2007.

[18] F. Xu, Z. Y. Yuan, G. H. Du, M. Halasa, and B. L. Su, "Highyield synthesis of single-crystalline $\mathrm{ZnO}$ hexagonal nanoplates and accounts of their optical and photocatalytic properties," Journal of Applied Physics A, vol. 86, no. 2, pp. 181-185, 2007.

[19] S. C. Navale and I. S. Mulla, "Photoluminescence and gas sensing study of nanostructured pure and $\mathrm{Sn}$ doped $\mathrm{ZnO}$," Materials Science and Engineering C, vol. 29, no. 4, pp. 1317-1320, 2009.

[20] Y. Cao, P. Hu, W. Pan, Y. Huang, and D. Jia, "Methanal and xylene sensors based on $\mathrm{ZnO}$ nanoparticles and nanorods prepared by room-temperature solid-state chemical reaction," Journal of Sensors and Actuators, B, vol. 134, no. 2, pp. 462466, 2008.

[21] S. G. Ansari, R. Wahab, Z. A. Ansari et al., "Effect of nanostructure on the urea sensing properties of sol-gel synthesized ZnO," Journal of Sensors and Actuators, B, vol. 137, no. 2, pp. 566-573, 2009.

[22] Z. Yang, Y. Huang, G. Chen, Z. Guo, S. Cheng, and S. Huang, "Ethanol gas sensor based on Al-doped $\mathrm{ZnO}$ nanomaterial with many gas diffusing channels," Journal of Sensors and Actuators, B, vol. 140, no. 2, pp. 549-556, 2009.

[23] C. Ge, Z. Bai, M. Hu, D. Zeng, S. Cai, and C. Xie, "Preparation and gas-sensing property of $\mathrm{ZnO}$ nanorod-bundle thin films," Journal of Materials Letters, vol. 62, no. 15, pp. 2307-2310, 2008.

[24] B. C. Yadav, R. Srivastava, C. D. Dwivedi, and P. Pramanik, "Moisture sensor based on $\mathrm{ZnO}$ nanomaterial synthesized through oxalate route," Journal of Sensors and Actuators, B, vol. 131, no. 1, pp. 216-222, 2008.

[25] Z. Liul, Z. Jin, W. Li, and J. Qiu, "Preparation of ZnO Porous Thin Films by Sol-Gel Method Using PEG Template," Journal of Materials Letters, vol. 59, pp. 3620-3625, 2005.

[26] M. Takata, D. Tsubone, and H. Yanagida, "Dependence of electrical conductivity of $\mathrm{ZnO}$ on degree of sintering," Journal of the American Ceramic Society, vol. 59, no. 1-2, pp. 4-8, 1976.

[27] C. Ge, C. Xie, and S. Cai, "Preparation and gas-sensing properties of Ce-doped $\mathrm{ZnO}$ thin-film sensors by dip-coating," Journal of Materials Science and Engineering B, vol. 137, no. 1-3, pp. 53-58, 2007.

[28] M. R. Vaezi, Ph.D. thesis, Sharif University of Technology, 2006. 

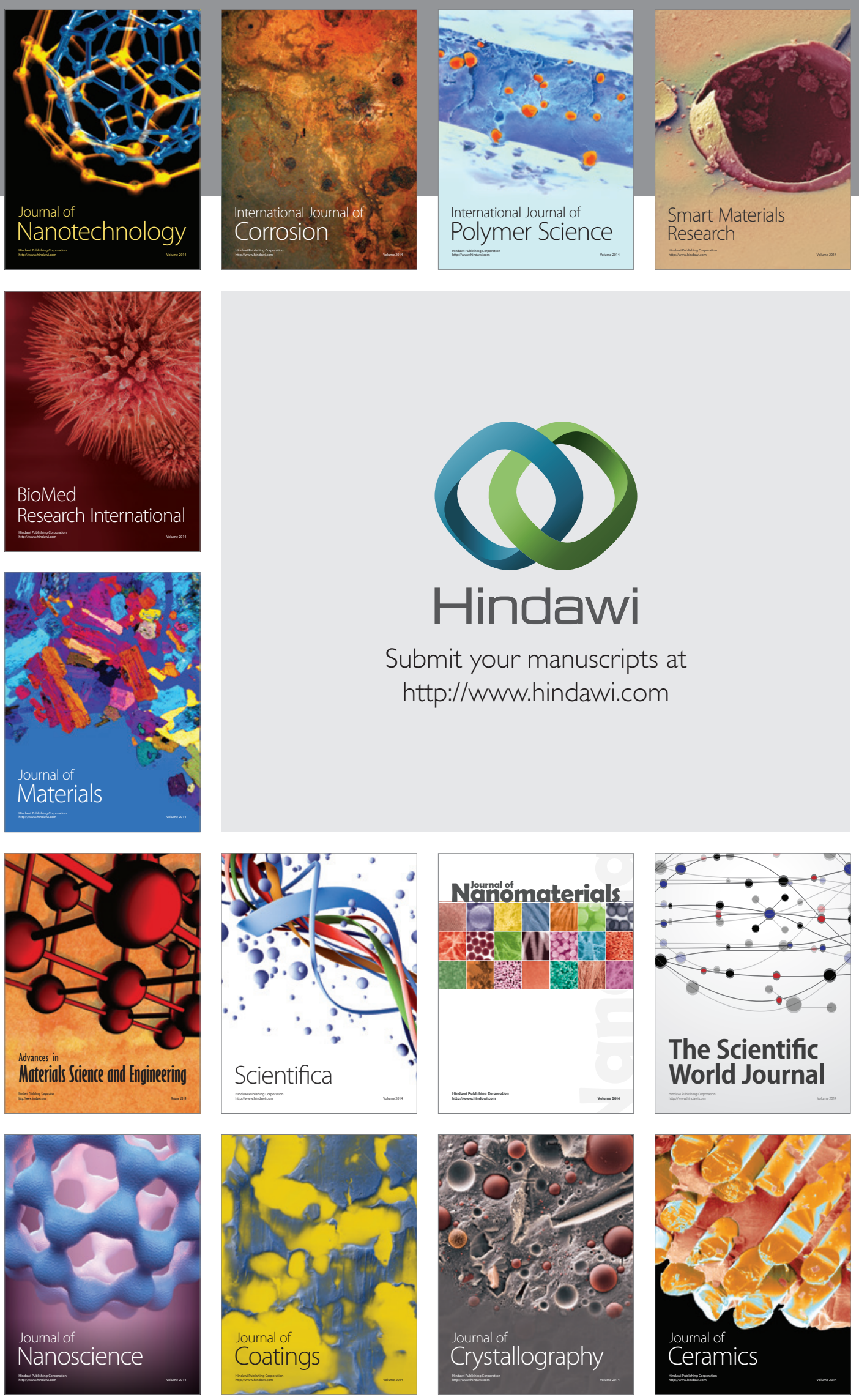

The Scientific World Journal

Submit your manuscripts at

http://www.hindawi.com

\section{World Journal}

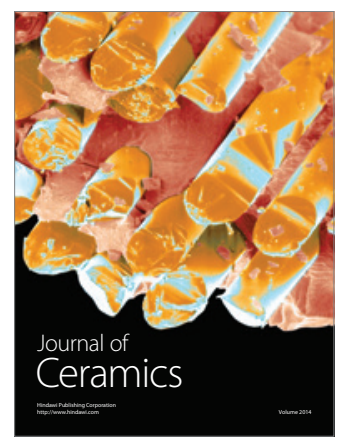

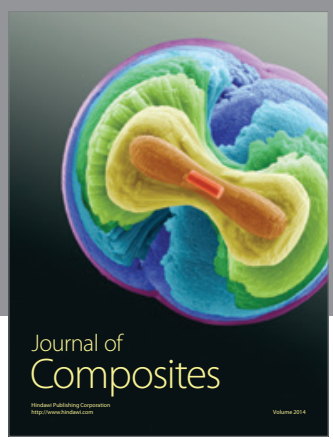
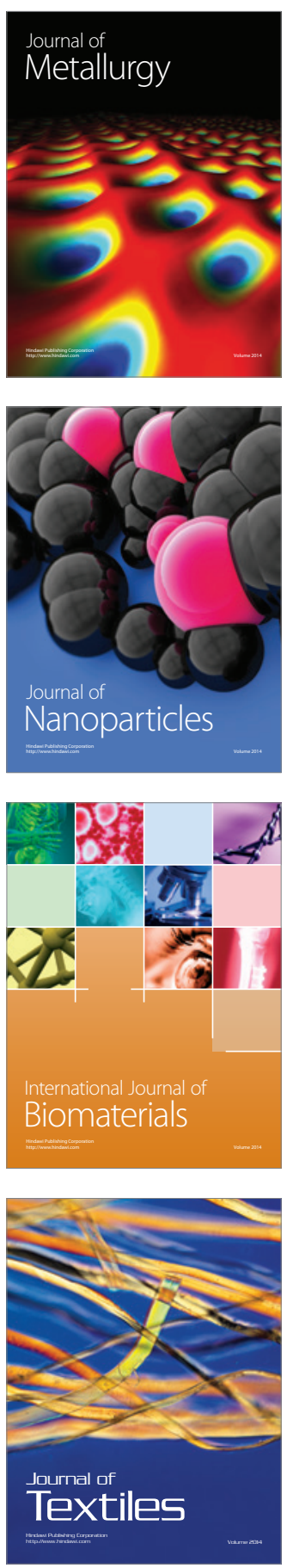